\title{
Disseminated Colitic Cancer Identified in Two Patients who had Undergone Surveillance Colonoscopies: A Case Report
}

Matsuda $\mathrm{K}^{1^{*}}$, Hashiguchi $\mathrm{Y}^{1}$, Asako $\mathrm{K}^{1}$, Ohno $\mathrm{K}^{1}$, Okada $\mathrm{Y}^{1}$, Tsukamoto $\mathrm{M}^{1}$, Fukushima $\mathrm{Y}^{1}$, Shimada $\mathrm{R}^{1}$, Ozawa $\mathrm{T}^{1}$, Hayama $\mathrm{T}^{1}$, Nozawa $\mathrm{K}^{1}$, Fukagawa $\mathrm{T}^{1}$, Sasajima $\mathrm{Y}^{2}$

${ }^{1}$ Departments of Surgery, Teikyo University School of Medicine, Tokyo, Japan

${ }^{2}$ Departments of Pathology, Teikyo University School of Medicine, Tokyo, Japan

Corresponding Author: Keiji Matsuda ${ }^{\text {ORCID ID }}$

Address: Department of Surgery, Teikyo University School of Medicine, 2-11-1 Kaga, Itabashi-ku, Tokyo 173-86o5, Japan; Tel: +81-3-3964-1211; Fax: +81-3-5375-6o97; Email: keiji@med.teikyo-u.ac.jp

Received date: 11 June 2020; Accepted date: 26 June 2020; Published date: 07 July 2020

Citation: Matsuda K, Hashiguchi Y, Asako K, Ohno K, Okada Y, Tsukamoto M, Fukushima Y, Shimada R, Ozawa T, Hayama T, Nozawa K, Fukagawa T, Sasajima Y. Disseminated Colitic Cancer Identified in Two Patients who had Undergone Surveillance Colonoscopies: A Case Report. Asp Biomed Clin Case Rep. 2020 Jul o7;3(2):151-59.

Copyright (c) 2020 Matsuda K, Hashiguchi Y, Asako K, Ohno K, Okada Y, Tsukamoto M, Fukushima Y, Shimada R, Ozawa T, Hayama T, Nozawa K, Fukagawa T, Sasajima Y. This is an open-access article distributed under the Creative Commons Attribution License, which permits unrestricted use, distribution, and reproduction in any medium provided the original work is properly cited.

\section{Abstract}

Background: It was reported that in surveillance colonoscopy (SC), targeted and random biopsies detected similar proportions of neoplasias. However, that study was conducted by experienced endoscopists familiar with colitic cancer. We report two cases of disseminated colitic cancer in patients who had undergone SC.

\section{Case Presentation:}

Case-1: A 69-year-old Japanese man first suffered from ulcerative colitis (UC) in 1979. Annual SCs had been performed since 1998. In 2017, colonoscopy confirmed a cancer in the ascending colon. A laparoscopy-assisted anal-preserving total proctocolectomy was performed in 2018. Histological findings showed the cancer reaching serosa and lymph node metastasis. Peritoneal dissemination occurred 1 year after the surgery. Two years after the first surgery, an ileostomy was created due to bowel obstruction caused by peritoneal dissemination.

Case-2: A 77-year-old Japanese man was diagnosed with UC at another hospital in 2010. SCs were performed annually since 2011. In April 2019, he developed frequent bowel movements, bleeding, and weight loss. Colonoscopy revealed stenosis at the rectum and sigmoid colon. The biopsy revealed adenocarcinoma. Laparoscopy-assisted surgery was performed in July 2019. The yellow ascites was aspirated and submitted for lavage cytology, which revealed signet-ring cell carcinoma. Many white nodules were found in the peritoneum and were diagnosed as peritoneal dissemination. A colostomy was performed. Chemotherapy was administered. Five months have passed since the operation, and the patient is alive.

Conclusion: Chromoendoscopy had not been performed in either patient. It is advisable to use chromoendoscopy when a target biopsy is performed.

\section{Keywords}

Ulcerative Colitis, Colitic Cancer, Advanced Cancer, Surveillance Colonoscopy 
Citation: Matsuda K, Hashiguchi Y, Asako K, Ohno K, Okada Y, Tsukamoto M, Fukushima Y, Shimada R, Ozawa T, Hayama T, Nozawa K, Fukagawa T, Sasajima Y. Disseminated Colitic Cancer Identified in Two Patients who had Undergone Surveillance Colonoscopies: A Case Report. Asp Biomed Clin Case Rep. 2020 Jul o7;3(2):151-59.

\section{Abbreviations}

SC: Surveillance Colonoscopy, UC: Ulcerative Colitis, OS: Overall Survival

\section{Background}

Surveillance colonoscopy (SC) is a strategy used to prevent invasive cancer by periodically performing a colonoscopy to find dysplasia [1]. SC is reported to be effective and to improve the overall survival (OS) of patients with ulcerative colitis (UC) [2]. The 5-year OS of the patients in that study's SC group was $89 \%$ and $70 \%$ in the non-SC group. Only $1.5 \%$ of the SC group turned out to be Stage IV, and non-curative surgery was performed in only $1 \%$ [2]. Regarding the methods of SC, a targeted biopsy is widely performed because random biopsies are considered time-consuming and costly [3]. A random controlled trial showed that targeted and random biopsies detected similar proportions of neoplasias [4], but that study was conducted by experienced endoscopists who were familiar with colitic cancer at a high-volume UC center and would not reflect real-world clinical practice. Herein we report the latest two consecutive cases of patients with disseminated colitic cancer despite having undergone SC.

\section{Case Presentation}

Case-1:

A 69-year-old Japanese man first suffered from UC in 1979. Annual SCs had been performed since 1998. In a)

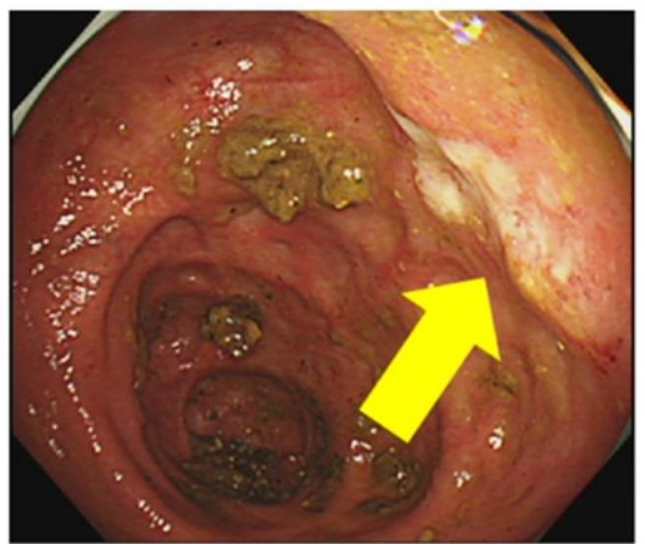

b)

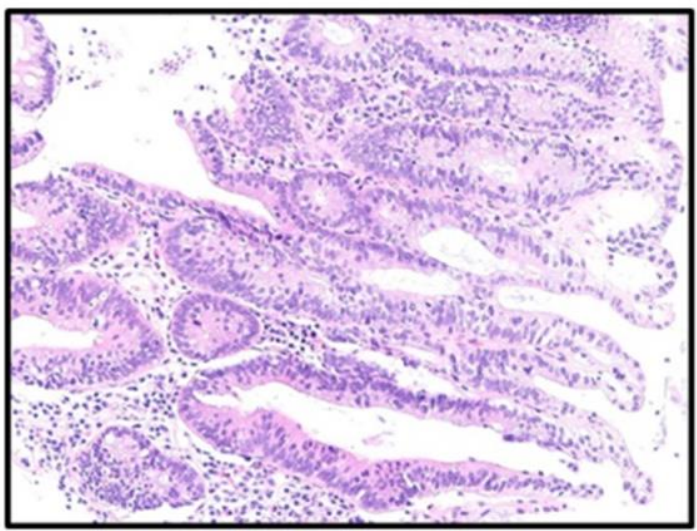

Fig-1:

Case-1. a: Colonoscopy showed an ulcerated lesion with short raised margins in the ascending colon (yellow arrow). b: A biopsy revealed tubular adenocarcinoma.

a)

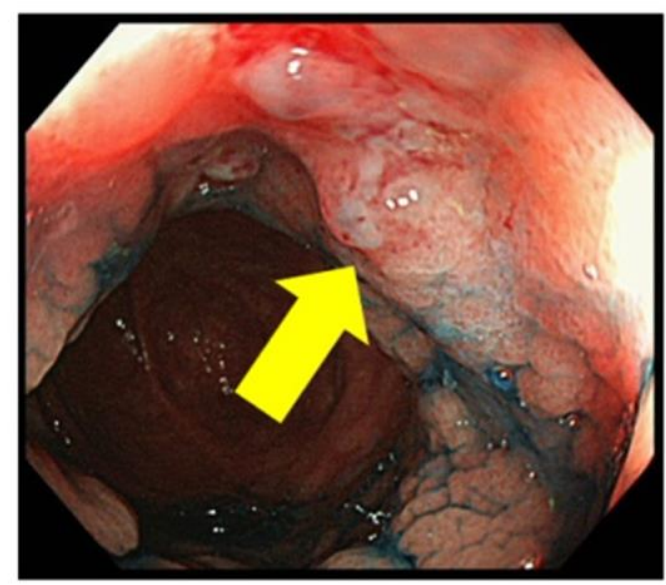

b)

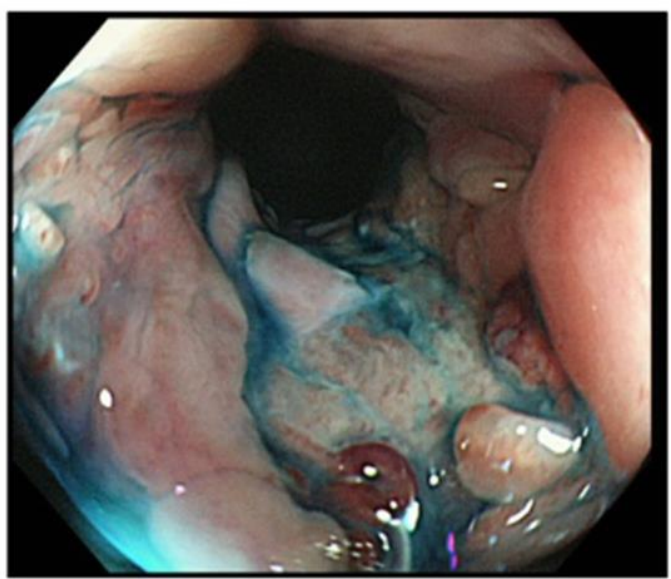

Fig-2:

a: Chromoendoscopy showed an ulcerated lesion with ambiguous boundaries in the ascending colon (yellow arrow). b: Chromoendoscopy revealed an ulcerated lesion in the anal canal, the biopsy specimens of which demonstrated no malignancy. 
Citation: Matsuda K, Hashiguchi Y, Asako K, Ohno K, Okada Y, Tsukamoto M, Fukushima Y, Shimada R, Ozawa T, Hayama T, Nozawa K, Fukagawa T, Sasajima Y. Disseminated Colitic Cancer Identified in Two Patients who had Undergone Surveillance Colonoscopies: A Case Report. Asp Biomed Clin Case Rep. 2020 Jul o7;3(2):151-59.

2016, endoscopic submucosal dissection was performed on 4-mm-sized low-grade dysplasia in the transverse colon. The patient's UC relapsed in February 2017. An ulcer in the ascending colon was confirmed by colonoscopy in July 2017 (Fig-1a). Biopsies were performed, revealing high grade dysplasia (Fig-1b). In December 2017 the patient was referred to the Teikyo IBD Center, and he was treated there with Pentasa ${ }^{\circledR}$ (mesalamine) alone. A steroid had been administered only in 1978, and he had no history of treatment with any biologics or immunomodulators. He was $173 \mathrm{~cm}$ tall and his weight was $57 \mathrm{~kg}$. The laboratory data were as follows: Hb $11.0 \mathrm{~g} / \mathrm{dl}$ (low), HT

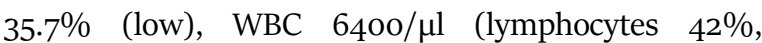
neutrophils 46\%), Alb 3.7g/dl (low), CRP o.62 mg/dL (high), CEA $1.4 \mathrm{ng} / \mathrm{ml}$, and CA19-9 $19.7 \mathrm{U} / \mathrm{ml}$. The number of bowel movements was 3-4/day, and the Bristol scale score was 5 . The patient showed no bleeding or abdominal pain. His clinical severity was mild. His Sutherland index [5] was 2. His father had suffered from esophageal cancer and his mother had suffered from colon cancer. In January 2018, a colonoscopy was performed at our hospital, revealing an ulcerative lesion with indistinct boundaries in the ascending colon (Fig-2a). Biopsy specimens revealed adenocarcinoma. There were multiple ulcers in the rectum (Fig-2b), and biopsy specimens showed no malignancy. The results of an enema indicated a $3-\mathrm{cm}$ trapezoidal deformity in the ascending colon (Fig-3). PET/CT showed an accumulation of 18-FDG only in the cancerous part.

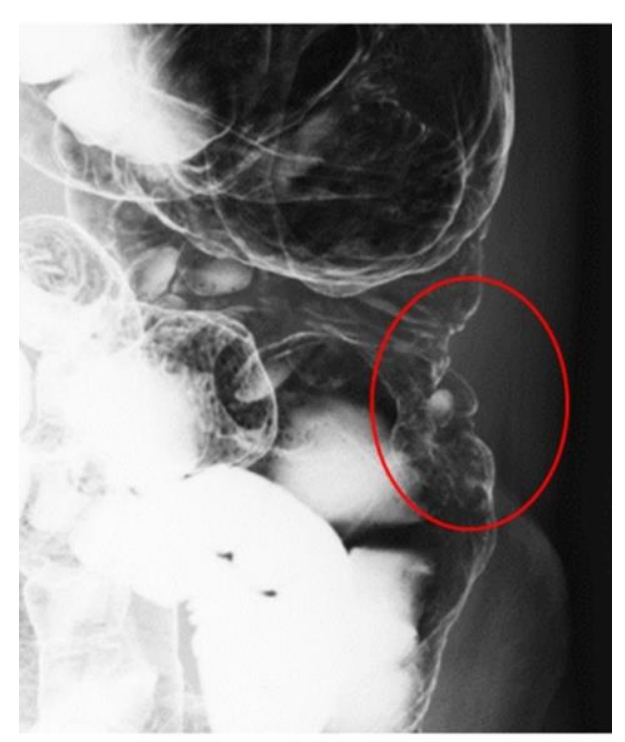

Fig-3: The results of an enema showed a $3-\mathrm{cm}$ trapezoidal deformity at the prone position (red circle).
In February 2018, the patient's colitic cancer at the ascending colon was treated with a laparoscopyassisted anal-preserving total proctocolectomy, the creation of a J-type ileal pouch, ileal pouch anal anastomosis, and ileostomy. The operating time was 8 $\mathrm{hr}$ and $45 \mathrm{~min}$, and the blood loss was $33 \mathrm{ml}$. The specimens showed an ulcerated lesion with ambiguous boundaries at the ascending colon (Fig-4). The histological examination demonstrated that the cancer

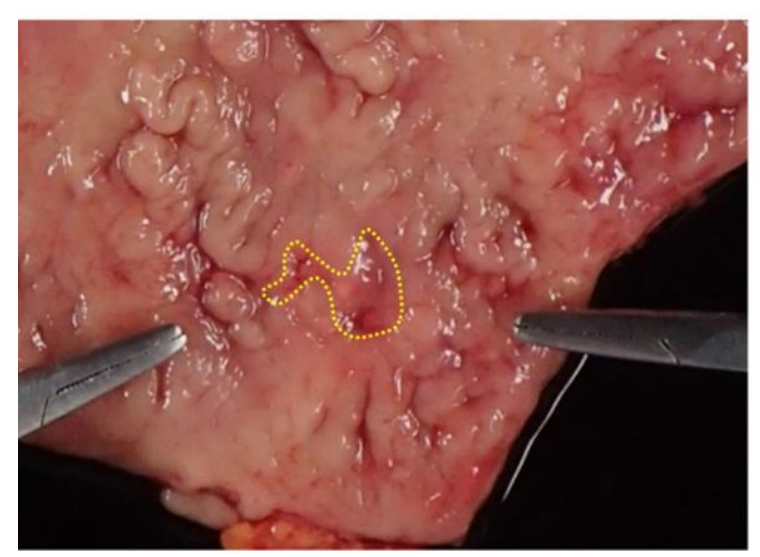

Fig-4: Macroscopic findings revealed an ulcerated lesion with ambiguous boundaries (yellow dotted line).

reached the serosal surface and was accompanied by cancerous lesions spreading in the mucosa around the ulcer (Fig-5 and Fig-6). The pathological report was as follows: A, pT4a, pN3 (Lymph node No. 203 positive), pType 3, 20×14 mm, tub2 >> por, int, INFb, lyo, vo, pPN1, pPMo (140 mm), pDMo (710 mm), pRMo, cMo, pStage IIIc [6]. The genetic test of cancer revealed KRAS mutation (G12D, G13D) and wild type for mismatch repair genes.

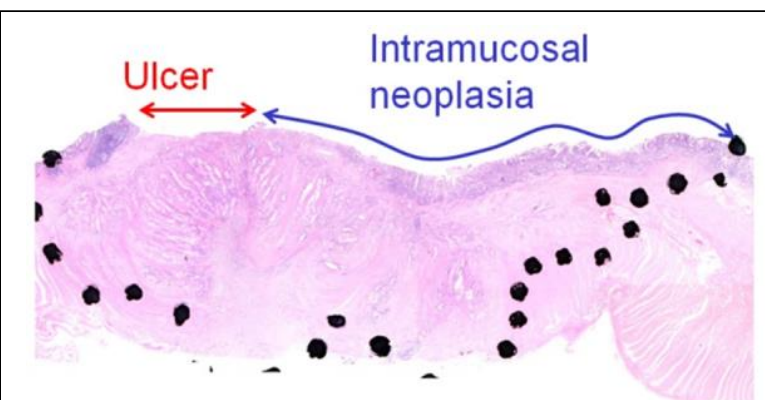

Fig-5: Microscopic findings of a cross section. Cancerous lesions were spreading in the mucosa around the ulcer. 
Citation: Matsuda K, Hashiguchi Y, Asako K, Ohno K, Okada Y, Tsukamoto M, Fukushima Y, Shimada R, Ozawa T, Hayama T, Nozawa K, Fukagawa T, Sasajima Y. Disseminated Colitic Cancer Identified in Two Patients who had Undergone Surveillance Colonoscopies: A Case Report. Asp Biomed Clin Case Rep. 2020 Jul o7;3(2):151-59.

a)

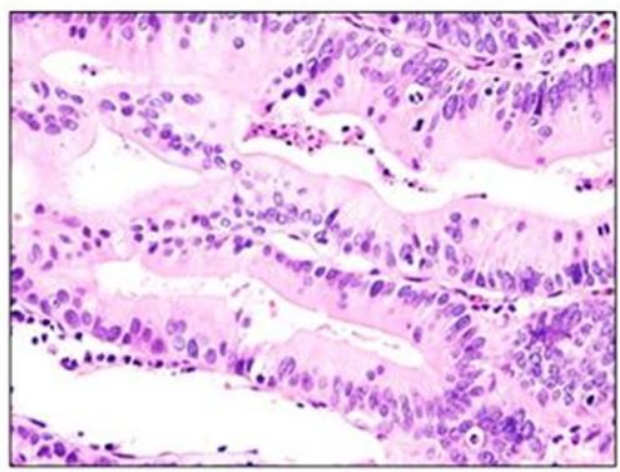

c)

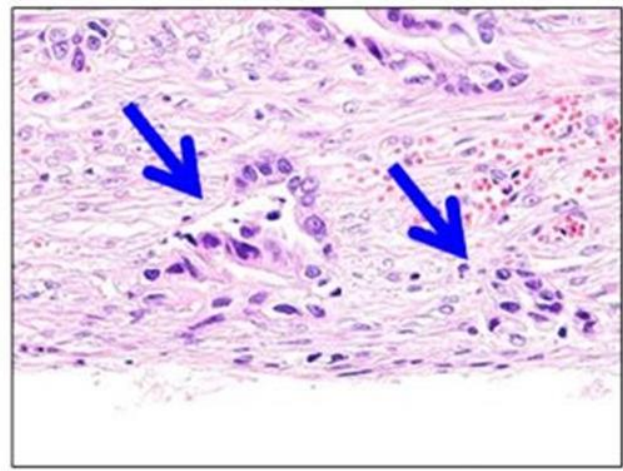

b)

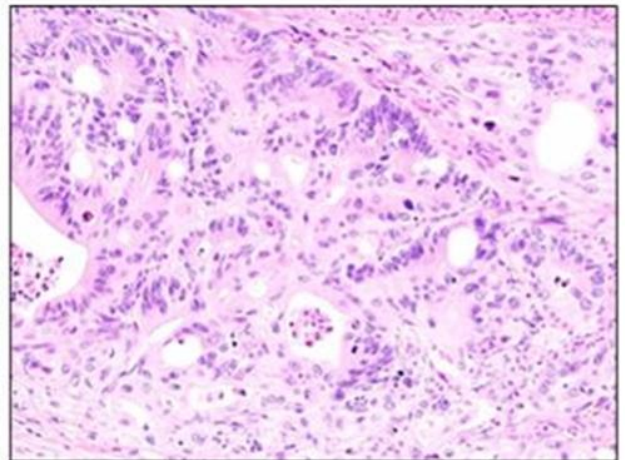

d)

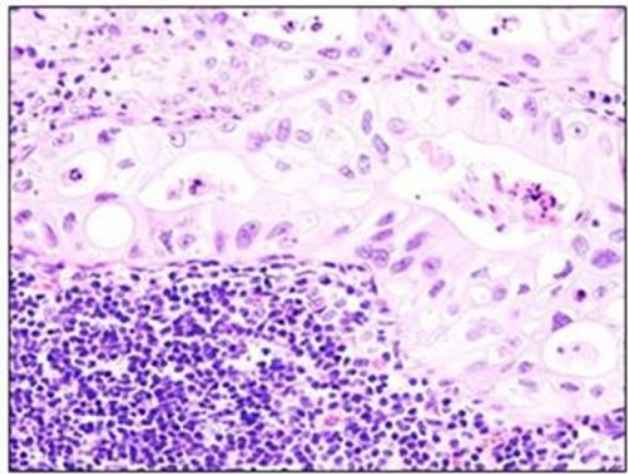

Fig-6:

Microscopic findings of intramucosal carcinoma (a: hematoxylin-eosin HE stain, х20o). Tubular adenocarcinoma in the muscularis propriae (b: HE stain, ×200). Carcinoma was reaching the serosal surface (c: HE stain, ×20o, blue arrows). Lymph node metastasis was observed (d: HE stain, х200).

The ileostomy was closed 3 months after the first surgery. The attending physician recommended adjuvant chemotherapy, but the patient refused. One year after the first surgery, peritoneal dissemination occurred. Chemotherapy was performed (1st line: BV + FOLFOX, 2nd line: BV + FOLFIRI). Two years after the first surgery, the patient was hospitalized due to bowel obstruction. Emergency surgery was performed, and it revealed that peritoneal dissemination had caused stricture of the ileum. Ascites cytology revealed adenocarcinoma. An ileostomy was created, and the patient remains alive 14 months after the first surgery.

\section{Case-2:}

A 77-year-old Japanese man developed diarrhea and was diagnosed with UC at another hospital in 2010. Surveillance colonoscopies were performed in Jan. 2011, Oct. 2012, Oct. 2013, Nov. 2014, Jan. 2017 and Jan. 2018. Colonoscopy performed in 2018 revealed an ulcer lesion with a raised swelling at the sigmoid colon, but the biopsy indicated no malignancy (Fig-7). In April 2019, the patient was hospitalized because of frequent bowel movements, bleeding, and weight loss (from $53 \mathrm{~kg}$ to $44 \mathrm{~kg}$ ). Colonoscopy revealed stenosis at the rectum and sigmoid colon. Four days later, balloon

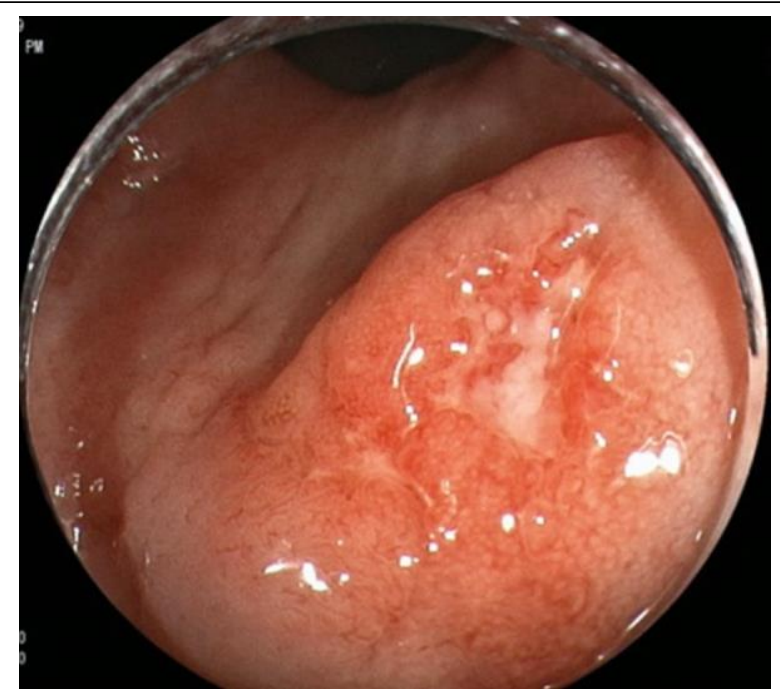

Fig-7: Case 2. Colonoscopy showed an ulc er lesion with a raised swelling at the sigmoid colon; the biopsy indicated no malignancy. 
Citation: Matsuda K, Hashiguchi Y, Asako K, Ohno K, Okada Y, Tsukamoto M, Fukushima Y, Shimada R, Ozawa T, Hayama T, Nozawa K, Fukagawa T, Sasajima Y. Disseminated Colitic Cancer Identified in Two Patients who had Undergone Surveillance Colonoscopies: A Case Report. Asp Biomed Clin Case Rep. 2020 Jul o7;3(2):151-59.

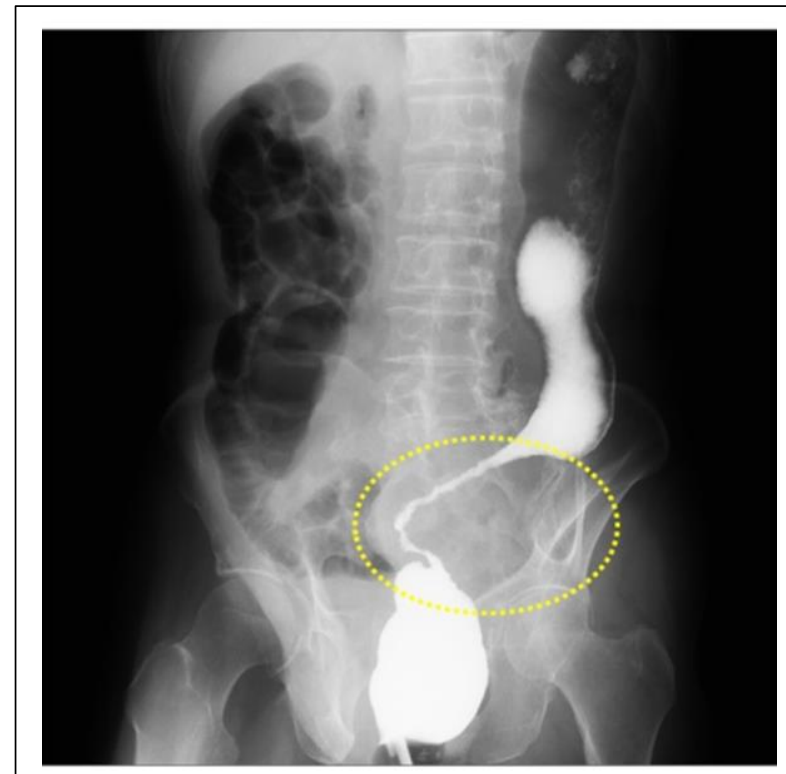

Fig-8: The results of an enema revealed strong stenosis in the sigmoid colon and rectum (yellow dotted circle).

dilatation was performed which enabled total colonoscopy using a small-diameter scope. The biopsy revealed adenocarcinoma. The patient was admitted to the Teikyo IBD Center in June 2019. He was taking oral medication for hypertension and had a history of schizophrenia and cerebral hemorrhage. His brother had liver cancer. The patient was $158 \mathrm{~cm}$ tall, and his weight was $44 \mathrm{~kg}$. The laboratory data were as follows:

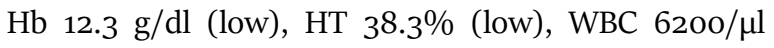
(lymphocytes 26\%, neutrophils 65\%), Alb $3.5 \mathrm{~g} / \mathrm{dl}$ (low), CRP o.83 mg/dL (high), CEA $10.2 \mathrm{ng} / \mathrm{ml}$ (high), and CA19-9 2.1 U/ml. The results of an enema showed strong stenosis in the sigmoid colon and rectum (Fig-8). Contrast-enhanced CT showed dilatation of the colon and wall thickening of the sigmoid colon and rectum (Fig-9a and Fig-9b).
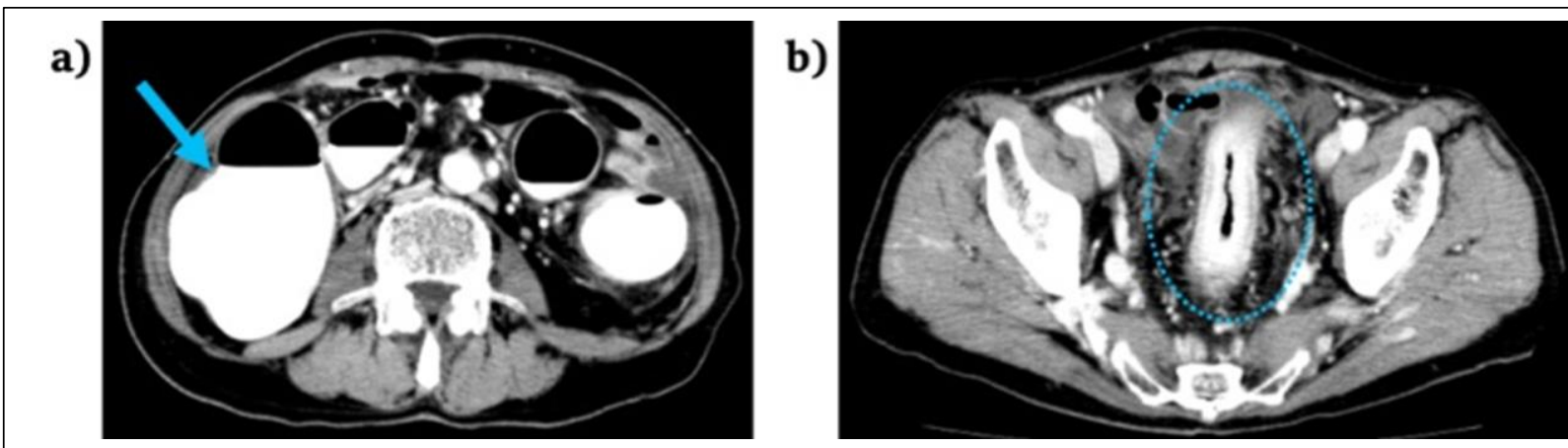

Fig-9:

Contrast-enhanced CT showed dilatation of the colon (a: blue arrow) and wall thickening of the sigmoid colon and rectum (9: blue dotted circle).

Colonoscopy at our hospital demonstrated rectal severe stenosis and rough mucosa, and the scope did not pass through the stenosis (Fig-10a). A biopsy showed tubular carcinoma and signet ring cell carcinoma (Fig-10b and Fig-10c). When the patient complained of strong abdominal pain, an X-ray examination revealed a large amount of gas in the small intestine and large intestine. Emergent laparoscopy-assisted surgery was performed in July 2019. The rectum and sigmoid colon were hard and thick, and the patient was judged to have type 4 colorectal cancer [6]. The yellow ascites at the pelvic floor was aspirated and submitted for lavage cytology. Many white nodules were found in the peritoneum,

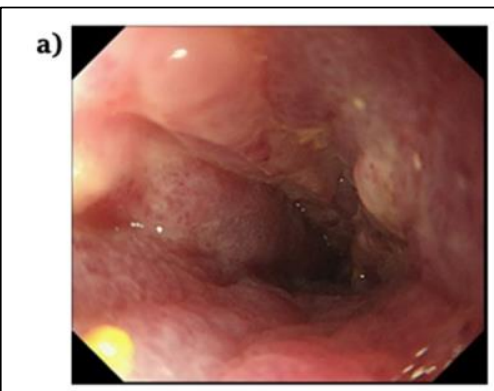

b)

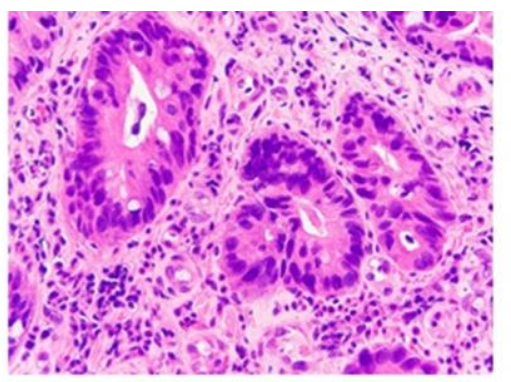

c)

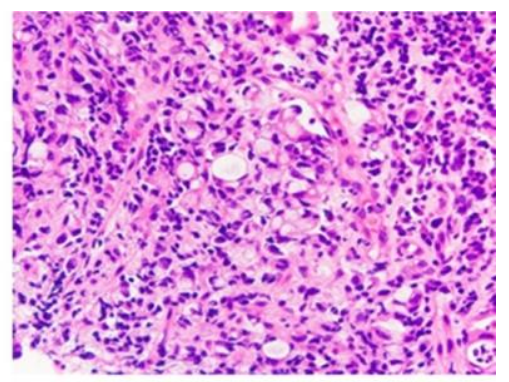

Fig-10:

Colonoscopy showed rectal severe stenosis (a). A biopsy showed tubular carcinoma (b) and signet ring cell carcinoma (c). 
Citation: Matsuda K, Hashiguchi Y, Asako K, Ohno K, Okada Y, Tsukamoto M, Fukushima Y, Shimada R, Ozawa T, Hayama T, Nozawa K, Fukagawa T, Sasajima Y. Disseminated Colitic Cancer Identified in Two Patients who had Undergone Surveillance Colonoscopies: A Case Report. Asp Biomed Clin Case Rep. 2020 Jul o7;3(2):151-59.

intestine, and mesentery and were diagnosed as peritoneal dissemination. A transverse colostomy was performed. Ascites cytology revealed signet-ring cell carcinoma (Fig-11). The genetic test of cancer revealed KRAS mutation $(\mathrm{G} 12 \mathrm{C})$ and wild type for BRAF.

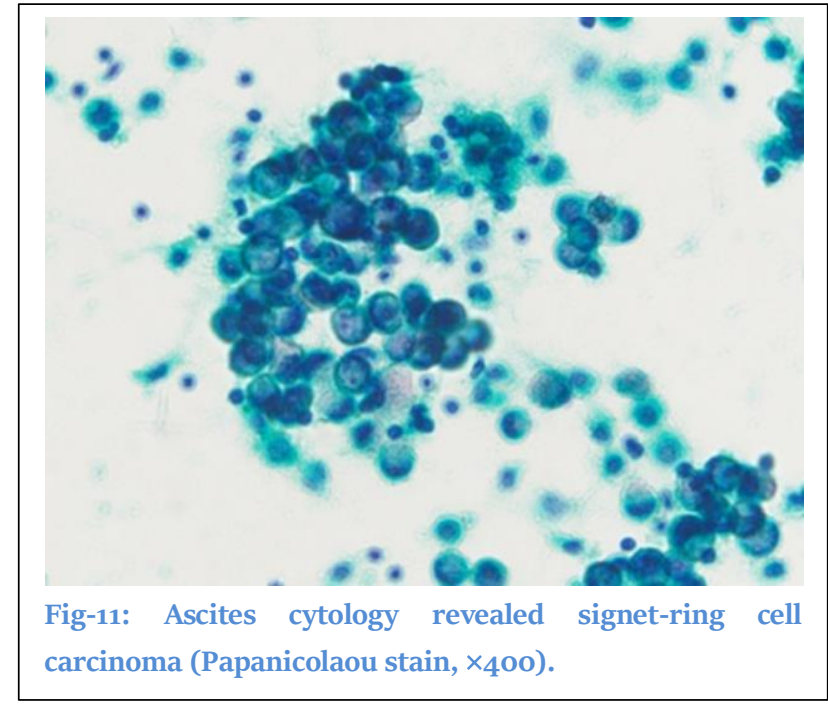

After leaving our hospital, chemotherapy was started at the previous hospital near the patient's home. Five months have passed since the operation, and the patient remains alive.

\section{Discussion}

Surveillance colonoscopy has been reported to detect colitic cancer at an early stage [7], leading to improved prognosis [2]. The tumor detection rate obtained by the SC method was comparable between a random group and a target group, and the costeffectiveness was better in the target group [4]. However, that study does not reflect real-world clinical practice as it was conducted by experienced endoscopists familiar with colitic cancer. Although the number of UC patients is increasing year by year, the total number of patients with UC in Japan is only $\sim 200,000$, and the number of colitic cancer patients is far less [8].

Restorative proctocolectomy is the representative surgery for UC and familial polyposis. Each year in Japan, a restorative proctocolectomy is performed in 400-500 patients [9]. Colitic cancer patients would be a part of this number and would be very few. In contrast, the annual number of new patients with sporadic non-UC colorectal cancer in Japan is roughly 100,000 [10]. Many endoscopists are familiar with
non-UC colorectal cancer, but not with colitic cancer. In fact, the two cases reported herein were found to have advanced cancer despite having undergone annual SCs performed by specialists certified by the Japan Gastroenterological Endoscopy Society.

The clinicopathological data of the colitic cancer patients treated at our hospital in the last 5 years are summarized in (Table-1). All of the patients underwent annual SCs. Case-1 was surgically resected, but recurrence was observed months later as dissemination, and the patient is undergoing chemotherapy. Case-2 had already shown peritoneal dissemination at the time of his diagnosis of colitic cancer, and his cancer was unresectable. Case- 3 and Case-4 underwent curative surgery and have not exhibited recurrence. Chromoendoscopy for Case-3 had been performed by injecting $0.3 \%$ indigo carmine into any lesions suspected of being neoplasia.

Several reports mentioned that Stage o-II colitic cancers were detected in $100 \%$ of patients who were undergoing annual SCs $[1,3]$, but the present two patients were identified in Stage III and IV despite their annual SCs. This indicates a gap in expertise between experienced hospitals and general hospitals. We speculate that the reasons for the difficulty in early detection in our patients' cases were as follows: Case-1 showed invasive-type cancer; the ulcer part was small with ambiguous boundaries, and the cancer's spread was deep without clear changes of the superficial layer. Case-2 showed diffusely invasive-type cancer and stenosis without forming a clear boundaries; his cancer might have spread quickly.

A study from the very experienced St. Mark's Hospital indicated that the numbers of colorectal cancers detected in their surveillance-detected group were as follows: Dukes' stage A $(n=24), B(n=10), C$ $(n=11)$, and D $(n=0)$ [11]. The percentage of Dukes' stage C was $24 \%$. Our Case-1, whose Dukes' stage was C (Stage III), would correspond to this. The numbers of colorectal cancers detected in the same study's interval group under per-protocol surveillance were: Dukes' stage A $(n=1), B(n=2), C(n=7)$, and D $(n=4)$. The percentage of Dukes' stage D was 28.5\%. Our Case-2, whose Dukes' stage was D (Stage IV), would correspond to this. That study [11] also summarized a 40-year analysis of SCs of patients with UC, and the 
Citation: Matsuda K, Hashiguchi Y, Asako K, Ohno K, Okada Y, Tsukamoto M, Fukushima Y, Shimada R, Ozawa T, Hayama T, Nozawa K, Fukagawa T, Sasajima Y. Disseminated Colitic Cancer Identified in Two Patients who had Undergone Surveillance Colonoscopies: A Case Report. Asp Biomed Clin Case Rep. 2020 Jul o7;3(2):151-59.

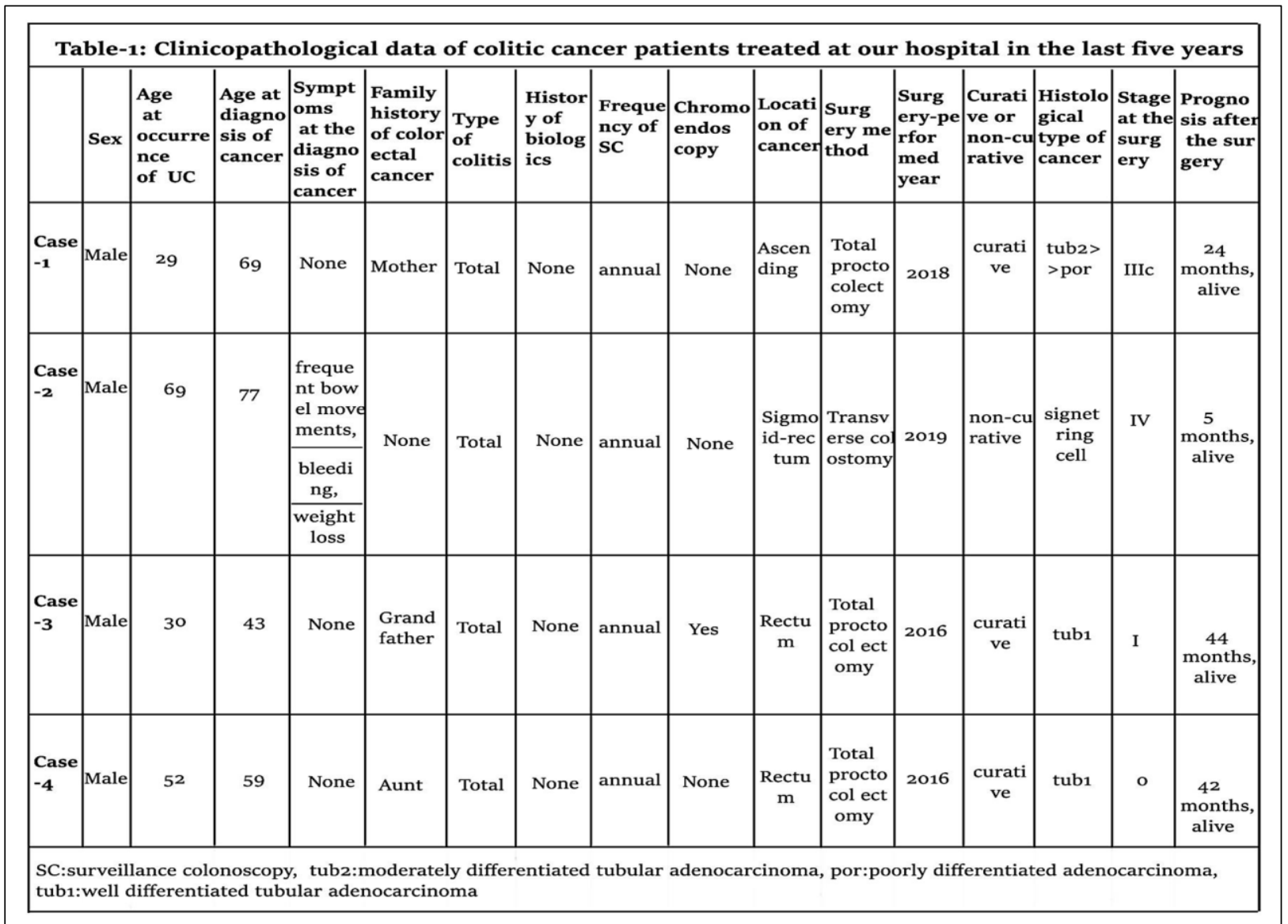

risk of interval cancer was rapidly decreasing. The study's authors reported that the performance of chromoendoscopy might have been a significant contributory factor in minimizing the risk of missing prior dysplastic lesions at colonoscopy [11].

The percentage of patients with dysplasia on targeted biopsies was reported to be $80.4 \%$ by standard-definition colonoscopy, $90.6 \%$ by highdefinition colonoscopy, and $90.2 \%$ by chromoendoscopy [12]. Our patients had not undergone chromoendoscopy during their SCs. Several guidelines have been published about SC for patients with ulcerative colitis. With regard to the SC interval, the American Gastroenterological Association (AGA) recommends annual or biannual SCs following the first SC for patients with ulcerative colitis, and after two negative examinations (no dysplasia or cancer), a further SC should be performed every 1-3 years [13]. The British Society of Gastroenterology (BSG) and the European Crohn's and Colitis Organisation (ECCO) recommend that SC should be conducted once every year, 3 years or 5 year based on the duration and extent of UC and additional risk factors [14,15]. Our two patients with disseminated cancer had undergone
SC annually with no chromoendoscopy, but another patient who had undergone SC with chromoendoscopy suffered from Stage I cancer, and he is alive without recurrence (Table-1).

The ECCO and the BSG have recommended chromoendoscopy in SC $[14,15]$. The BSG guidelines state that if chromoendoscopy is not used, the random biopsy strategy should be followed. The European Society of Gastrointestinal Endoscopy contends that in settings with experienced endoscopists, the use of random biopsies can be abandoned [16]. On the other hand, a systematic review indicated that only lowquality evidence supported the concept that chromoendoscopy was superior to standard-definition white-light endoscopy [17]. In settings with insufficiently experienced endoscopists or in the situation of active disease, the random biopsy strategy should not be abandoned.

In conclusion, we treated two consecutive patients with disseminated colitic cancer who had undergone SC. Colitic cancer is rare, and only a few experienced endoscopists are familiar with it. In clinical practice, chromoendoscopy should be adopted when target 
Citation: Matsuda K, Hashiguchi Y, Asako K, Ohno K, Okada Y, Tsukamoto M, Fukushima Y, Shimada R, Ozawa T, Hayama T, Nozawa K, Fukagawa T, Sasajima Y. Disseminated Colitic Cancer Identified in Two Patients who had Undergone Surveillance Colonoscopies: A Case Report. Asp Biomed Clin Case Rep. 2020 Jul o7;3(2):151-59.

Case Report

biopsies are performed in surveillance colonoscopy for patients with ulcerative colitis.

\section{Authors' contributions}

KM designed and conducted the research and wrote the manuscript. YH drafted the manuscript, revised it critically for important intellectual content, and gave final approval for the content. K.A., K.O., Y.O., M.T., Y.F., R.S., T.O., T.H., K.N., and T.F. contributed to the daily medical treatment of the cases. YS contributed to the pathological diagnoses. All authors approved the final version of the manuscript to be submitted.

\section{Conflict of interest}

None of the authors have personal or financial conflicts to declare.

\section{Human and animal rights statement}

All the procedures followed have been performed in accordance with the ethical standards laid down in the 1964 Declaration of Helsinki and its later amendments.

\section{Informed consent}

Informed consent was obtained from the patients for being included in the study.

\section{References}

[1] Hata K, Watanabe T, Kazama S, Suzuki K, Shinozaki M, Yokoyama T, Matsuda K, Muto T, Nagawa H. Earlier surveillance colonoscopy programme improves survival in patients with ulcerative colitis associated colorectal cancer: results of a 23-year surveillance programme in the Japanese population. Br J Cancer. 2003 Oct 6;89(7):1232-36. [PMID: 14520452]

[2] Hata K, Anzai H, Ikeuchi H, Futami K, Fukushima K, Sugita A, Uchino M, Higashi D, Itabashi M, Watanabe K, Koganei K, Araki T, Kimura H, Mizushima T, Ueda T, Ishihara S, Suzuki Y; Research Group for Intractable Inflammatory Bowel Disease of the Ministry of Health, Labour and Welfare of Japan (RGIBD). Surveillance Colonoscopy for Ulcerative Colitis-Associated Colorectal Cancer Offers Better Overall Survival in Real-World Surgically Resected Cases. Am J Gastroenterol. 2019 Mar;114(3):483-89. [PMID: 30747769]

[3] Kamiya T, Ando T, Watanabe O, Nakamura M,
Yamamura T, Miyahara R, Hirooka Y, Goto $H$. Suitability of surveillance colonoscopy for patients with ulcerative colitis to detect colorectal cancer: current guidelines miss some early-stage cases. Nagoya J Med Sci. 2015 Feb;77(1-2):237-44. [PMID: 25797989]

[4] Watanabe T, Ajioka Y, Mitsuyama K, Watanabe K, Hanai H, Nakase H, Kunisaki R, Matsuda K, Iwakiri R, Hida N, Tanaka S, Takeuchi Y, Ohtsuka K, Murakami K, Kobayashi K, Iwao Y, Nagahori M, lizuka B, Hata K, Igarashi M, Hirata I, Kudo SE, Matsumoto T, Ueno F, Watanabe $\mathrm{G}$, Ikegami $\mathrm{M}$, Ito $\mathrm{Y}$, Oba $\mathrm{K}$, Inoue $\mathrm{E}$, Tomotsugu N, Takebayashi T, Sugihara K, Suzuki Y, Watanabe M, Hibi T. Comparison of Targeted vs Random Biopsies for Surveillance of Ulcerative ColitisAssociated Colorectal Cancer. Gastroenterology. 2016 Dec;151(6):1122-30. [PMID: 27523980]

[5] Sutherland LR, Martin F, Greer S, Robinson M, Greenberger N, Saibil F, Martin T, Sparr J, Prokipchuk E, Borgen L. 5-Aminosalicylic acid enema in the treatment of distal ulcerative colitis, proctosigmoiditis, and proctitis. Gastroenterology. 1987 Jun;92(6):189498. [PMID: 3569765]

[6] Hashiguchi Y, Muro K, Saito Y, Ito Y, Ajioka Y, Hamaguchi T, Hasegawa K, Hotta K, Ishida H, Ishiguro M, Ishihara S, Kanemitsu Y, Kinugasa Y, Murofushi K, Nakajima TE, Oka S, Tanaka T, Taniguchi H, Tsuji A, Uehara K, Ueno H, Yamanaka T, Yamazaki K, Yoshida M, Yoshino T, Itabashi M, Sakamaki K, Sano K, Shimada Y, Tanaka S, Uetake H, Yamaguchi S, Yamaguchi N, Kobayashi H, Matsuda K, Kotake K, Sugihara K; Japanese Society for Cancer of the Colon and Rectum. Japanese Society for Cancer of the Colon and Rectum (JSCCR) guidelines 2019 for the treatment of colorectal cancer. Int J Clin Oncol. 2020 Jan;25(1):142. [PMID: 31203527]

[7] Singh K, Al Khoury A, Kurti Z, Gonczi L, Reinglas J, Verdon C, Kohen R, Bessissow T, Afif W, Wild G, Seidman E, Bitton A, Lakatos PL. High Adherence to Surveillance Guidelines in Inflammatory Bowel Disease Patients Results in Low Colorectal Cancer and Dysplasia Rates, While Rates of Dysplasia are Low Before the Suggested Onset of Surveillance. J Crohns Colitis. 2019 Sep 27;13(10):1343-50. [PMID: 30918959] [8] Japan Intractable Diseases Information Center. Ulcerative colitis (designated intractable disease 97). Kaidai University; 2019. Available from: https://www.nanbyou.or.jp/entry/62

[9] Uchino M, Ikeuchi H, Hata K, Okada S, Ishihara S, 
Citation: Matsuda K, Hashiguchi Y, Asako K, Ohno K, Okada Y, Tsukamoto M, Fukushima Y, Shimada R, Ozawa T, Hayama T, Nozawa K, Fukagawa T, Sasajima Y. Disseminated Colitic Cancer Identified in Two Patients who had Undergone Surveillance Colonoscopies: A Case Report. Asp Biomed Clin Case Rep. 2020 Jul o7;3(2):151-59.

Morimoto K, Sahara R, Watanabe K, Fukushima K, Takahashi K, Kimura H, Hirata K, Mizushima T, Araki T, Kusunoki M, Nezu R, Nakao S, Itabashi M, Hirata A, Ozawa H, Ishida T, Okabayashi K, Yamamoto T, Noake T, Arakaki J, Watadani Y, Ohge H, Futatsuki R, Koganei K, Sugita A, Higashi D, Futami K. Changes in the rate of and trends in colectomy for ulcerative colitis during the era of biologics and calcineurin inhibitors based on a Japanese nationwide cohort study. Surg Today. 2019 Dec;49(12):1066-73. [PMID: 31309329]

[10] National Cancer Center. Latest cancer statistics; 2020. Available from:

https://ganjoho.jp/reg_stat/statistics/stat/summary.ht $\mathrm{ml}$

[11] Choi CH, Rutter MD, Askari A, Lee GH, Warusavitarne J, Moorghen M, Thomas-Gibson S, Saunders BP, Graham TA, Hart AL. Forty-Year Analysis of Colonoscopic Surveillance Program for Neoplasia in Ulcerative Colitis: An Updated Overview. Am J Gastroenterol. 2015 Jul;110(7):1022-34. [PMID: 25823771]

[12] Beintaris I, Rutter M. Advanced imaging in colonoscopy: contemporary approach to dysplasia surveillance in inflammatory bowel disease. Frontline Gastroenterol. 2016 Oct;7(4):308-15. [PMID: 28839872]

[13] Farraye FA, Odze RD, Eaden J, Itzkowitz SH, McCabe RP, Dassopoulos T, Lewis JD, Ullman TA, James $\mathrm{T}$ 3rd, McLeod R, Burgart LJ, Allen J, Brill JV; AGA Institute Medical Position Panel on Diagnosis and Management of Colorectal Neoplasia in Inflammatory Bowel Disease. AGA medical position statement on the diagnosis and management of colorectal neoplasia in inflammatory bowel disease. Gastroenterology. 2010 Feb;138(2):738-45. [PMID: 20141808]

[14] Mowat C, Cole A, Windsor A, Ahmad T, Arnott I, Driscoll R, Mitton S, Orchard T, Rutter M, Younge L, Lees C, Ho GT, Satsangi J, Bloom S; IBD Section of the British Society of Gastroenterology. Guidelines for the management of inflammatory bowel disease in adults. Gut. 2011 May;6o(5):571-6o7. [PMID: 21464096]

[15] Magro F, Gionchetti P, Eliakim R, Ardizzone S, Armuzzi A, Barreiro-de Acosta M, Burisch J, Gecse KB, Hart AL, Hindryckx P, Langner C, Limdi JK, Pellino G, Zagórowicz E, Raine T, Harbord M, Rieder F; European Crohn's and Colitis Organisation [ECCO]. Third European Evidence-based Consensus on Diagnosis and Management of Ulcerative Colitis. Part 1: Definitions, Diagnosis, Extra-intestinal Manifestations, Pregnancy, Cancer Surveillance, Surgery, and Ileo-anal Pouch Disorders. J Crohns Colitis. 2017 Jun 1;11(6):649-70. [PMID: 28158501]

[16] Bisschops R, East JE, Hassan C, Hazewinkel Y, Kamiński MF, Neumann H, Pellisé M, Antonelli G, Bustamante Balen M, Coron E, Cortas G, Iacucci M, Yuichi M, Longcroft-Wheaton G, Mouzyka S, Pilonis N, Puig I, van Hooft JE, Dekker E. Advanced imaging for detection and differentiation of colorectal neoplasia: European Society of Gastrointestinal Endoscopy (ESGE) Guideline - Update 2019. Endoscopy. 2019 Dec;51(12):1155-79. [PMID: 31711241]

[17] Bessissow T, Dulai PS, Restellini S, Landry T, Bisschops R, Murad MH, Singh S. Comparison of Endoscopic Dysplasia Detection Techniques in Patients With Ulcerative Colitis: A Systematic Review and Network Meta-analysis. Inflamm Bowel Dis. 2018 Nov 29;24(12):2518-26. [PMID: 2984660o] 